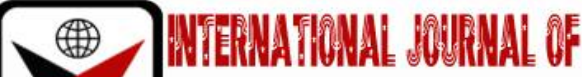

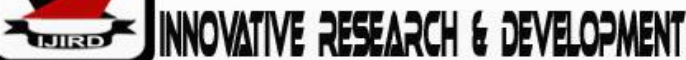

ISSN 2278 - 0211 (Online)

\section{Risk Factors Associated with Livestock Feeding and Disease Control Practices in the Peri-Urban Slums of Kisumu City, Kenya}

\begin{tabular}{|c|}
\hline Charles Muleke Inyagwa \\
Associate Professor, Department of Veterinary Medicine and Surgery, \\
Egerton University, Kenya \\
Wekesa Sabesia \\
Kenneth Orengo \\
Senior Research Officer, Central Veterinary Investigation Laboratories, Kabete, Kenya \\
Penior Research Officer, Central Veterinary Investigation Laboratories, Kabete, Kenya \\
Price Amanya \\
Research Assistant, Department of Agricultural Economics and Agri-Business Management, \\
Egerton University, Kenya \\
Raymond Mdachi \\
Senior Research Officer, Kenya Agricultural and Livestock Research Organization, Kenya
\end{tabular}

\begin{abstract}
:
Livestock feeding practices present food safety concerns to consumers who are aware of food safety and their linkage to feeding practices. Domesticated animals kept in the peri-urban territories often feed on waste dump feeds and polluted waters. Consequently, animal feeds could be contaminated with potentially toxic metals and diseases which may lead to death and economic losses in lost trade opportunities. Objective of this study was to determine the risk factors associated with livestock feeding and disease control practices in the peri-urban slums of Kisumu City, Kenya. This was achieved through identifying, characterizing and disseminating peri-urban livestock feeding practices and constraints, and their effects on food safety as well as general well-being of livestock. Primary data was collected from 291 randomly selected smallholder livestock farmers in the peri-urban slums of the City by use of semi-structured questionnaires. Descriptive statistics inform of cross tabulations, means and frequencies were used to characterize peri-urban livestock feeding and disease control practices. The results revealed that $58 \%$ of the county residents were male while $42 \%$ were female. Their ages ranged between 18 and 90years with a mean age of 55. Majority (74\%) practiced both livestock and crop production while 26\% kept livestock only. The farmers mainly kept indigenous cattle (97\%) as opposed to exotic (3\%). The prevalent livestock farming system was free range (93\%) where most farmers grazed their livestock on open unutilized spaces and dump sites. Animals were kept for consumption (62\%) and for income generation (32\%). The main production constraints identified by farmers were diseases (65\%) and lack of feed (20\%). The diseases varied with region and animal species which included tick-borne diseases (53\%) and foot and mouth (15\%). Farmers obtained information on management and treatment of livestock largely from private veterinarians (64\%). There is need to create policies on peri-urban slum livestock keeping practices, and waste management to reduce the risks associated with livestock feeding and diseases in Kisumu city.
\end{abstract}

Keywords: Food safety risks, peri-urban, livestock feeding, Kisumu County

\section{Introduction}

Livestock keeping in peri-urban areas nourishment security and gives effectively convertible resources that empower the poor to have money to cover school fees, medicinal costs and day to day financial requirements (Schiere, 2000). Embracing peri-urban livestock rearing empowers the poor to broaden livelihood opportunities with available choices to the susceptible groups. Food safety is a growing concern in the peri-urban areas dependent on food chains (Shimshoni, 2017). Safe, good quality sustenance is vital to food security, general wellbeing and monetary improvement since it promotes trade. The production of safe food of animal origin is the task of livestock farmers, animal feed suppliers, public health officials and extension agents who are deemed stakeholders. Majority of livestock keepers in the peri-urban focuses are susceptible groups of female headed family units, youths, retired individuals, widows and the less educated who regularly utilize tainted water for domesticated animals because of poverty and scarcity of resources. The wastewater and fertilizer residue released locally are of ecological concerns (FAO, 2007). 
Livestock feeding practices impacts candidly on the production of safe nourishment, trading of food and sustenance security (Barnes, 2018). To guarantee food sanitation, security and non-interruption of trade, code of practice on good animal feeding (CAC/RCP, 2004) was launched in 2004 for joint implementation efforts including national experts and the private sector (FAO, 2007). The target of the code is to guarantee safe human nourishment utilization through adherence to great animal feeding practices at the ranch level and Good Manufacturing Practices(GMPs) during procurement, handling, processing, preparing and dissemination of animal feed and feed ingredients for sustenance producing animals. The Code applies to the production and utilization of all materials bound for animal feed and feed ingredients at all dimensions, regardless of whether delivered modernly or at homestead level. This encompasses grazing or free-range feeding, forage crop and aquaculture.

Majority of primary, secondary and key stakeholders involved in peri-urban livestock keeping sector are unaware of the use of the Codex Code of Practice on Good Animal Feeding for limiting potential risks. With livestock population steadily increasing with the development of human masses in the urban slums, there is need to train food safety regulators, inspectors, feed and livestock industry personnel, and farmers for the production of safe feed (Waters, 2016).Kisumu town, a lakeside city in western Kenya, is predominated with small enterprises dealing with metal works, car garages (Jua Kali Sheds) and construction works that pose a risk of contamination to the environment with hazardous substances including heavy metals. Kisumu County government collects and dump solid wastes at a Nyalenda - Kachok dumpsite. The waste is mainly from the city's supermarkets, industries, petrol stations, residences and markets.

Peri-urban livestock farmers tend to graze or harvest grass around this dumpsite due to scarcity of adequate feeds and water. Nonetheless, peri-urban livestock farmers in Kisumu municipality also graze livestock near the dumpsite and utilize water ponds as animal drinking water which may be contaminated. This presents high risk of food contamination along the animal-human food chain from heavy metals and microbial pathogens. Furthermore, the fundamental focal point of previous studies on farming advancement activities has been on rustic regions with the view that improved sustenance generation in rustic zones can supply the extending urban populace. This has largely neglected peri-urban agriculture, risk factors associated with urban livestock feeding practices as well implications on food safety and security. It is therefore on this basis that this study is geared toward filling the knowledge gap on risk factors associated with livestock feeding and disease control practices in Kisumu County, Kenya. Objective of this study was to identify, characterize and disseminate peri-urban livestock feeding practices and constraints, and their ramifications on food safety as well as general well-being of livestock. This study also contributes to the body of knowledge on developing and maintaining a food safety system from farm to table involving all the stakeholders along the food chain for enhanced food safety from livestock reared in the urban slums of Kisumu city, Kenya.

\section{Methodology}

\subsection{Study Area}

The study was undertaken at the shore of Lake Victoria, Kisumu city and its environs within the area limits of $00^{\circ}$ $51^{\prime}$ South and Longitude $00^{\circ} 41^{\prime}$ North and longitudes $33^{\circ} 20^{\prime}-35^{\circ} 20^{\prime}$ East and an altitude of 528 meters above the sea level. Location of the study sites within peri-urban areas of Kisumu city were as follows: Sites 1: Nyalenda Obunga, Manyatta - Kachok: whose animals feed and graze at the dumping site in urban slums - suspected to be polluted with the metals. Sites 2: Nyamasaria, Mamboleo lie in a peri-urban area: $8 \mathrm{~km}$ - north eastern outskirts of the city with relative high animal husbandry. Site 3: Otonglo located in Chiga: $8 \mathrm{~km}$ - eastern outskirts of the city slums with subsistence with light animal husbandry. The choice of the sites 2 and 3 was based on the fact that animals graze freely in these areas but cannot reach the dumping site where only those from site 1 (Nyalenda, Obunga, Manyatta, Kochak) access for forage. Nearly $65 \%$ of Kisumu's population subsists in the informal settlements and an additional $50 \%$ of the inhabitants are engaged in some type of urban agriculture and livestock keeping, (Ishagiet al., 2002).

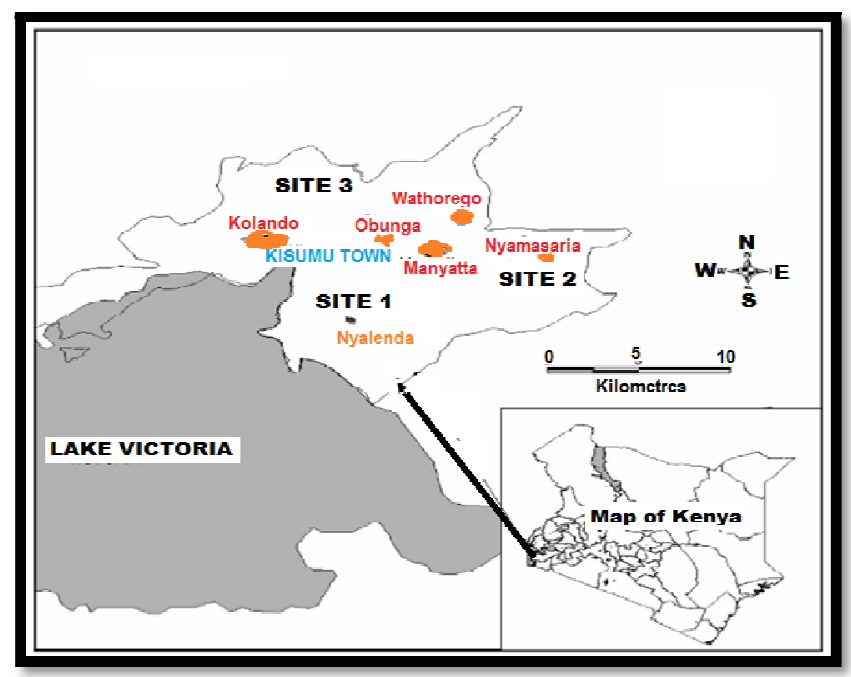

Figure 1: Map of Kenya (Inset), Bolded the Study Sites 1, 2 And 3 in the Peri-Urban Precincts of Kisumu City (Courtesy: Maoulidi, M., 2012) 


\subsection{Research Design and Data Management}

Field visits were undertaken to purposely select study sites 1, 2 and 3(see Fig. 1) in collaboration with the County/ Sub-County Veterinary Officers, Sub-County and Ward administration personnel. Study sites headed by village/ward chairperson were demarcated on the basis of having a higher concentration of livestock keeping in the urban and peri-urban areas within Kisumu city. At each study site, the farmers were randomly selected based on a list from previous animal disease vaccination campaigns availed by the county and sub-county veterinary officers in Kisumu County. A semi-structured pre-tested questionnaire was administered to household heads or responsible persons (if the household head was not available) using swahili language, which is common in the area. Primary data was collected from 291 randomly selected smallholder livestock farmers in the urban and peri-urban slums within city. The questionnaires addressed: farmer characteristics, spatial attributes, size of land, system of tenure, livestock kept on the farm, production systems and disease constraints, administration practices, milk production, and regular illnesses at farm level. Descriptive statistics in form of cross tabulations, means and frequencies were used to identify and characterize the risk factors associated with livestock feeding and disease control practices in the city slums. Data management involved cleaning the filled questionnaires for errors and coding of the statistical variables. Data was then analyzed using the Statistics Computer Program (Stata Corp 2011) to characterize and identify distinct groups by the production objectives, level of regulatory supervision on food safety, level of market orientation, level of consumer pressure for compliance with food safety and quality controls, education level and farmer experience of the farmers.

\section{Results}

\subsection{Farmer Socio-Economic Characteristics in the Peri-Urban Slums of Kisumu City}

The results indicate that $58 \%$ of the respondents were male while $42 \%$ were female (see Table 1 ). Majority (25\%) of the respondents were aged between 61 to 70 years with an overall sample mean age of 55 years (see Table 2). Thirty six percent $(36 \%)$ of the farmers had reached upper primary level of education, $27 \%$ had secondary education, $14 \%$ had no formal education, $13 \%$ had lower primary education and $10 \%$ had attained tertiary level of education such as colleges and universities (see Table 1). Inhabitants were educated with over 9 years of schooling with a mean of 7 members per household (see Table 2). Fifty one percent (51\%) of respondents did not engage in other off-farm activities besides farming practices while $49 \%$ participated in other non-farming practices such as fishing, masonry (see Table 1). Twenty nine percent (29\%) of respondents were occupied with shops and kiosks, masonry and carpentry (5\%), livestock trading (1\%), fishing (2\%) and other occupations (12\%) (see Table 1).

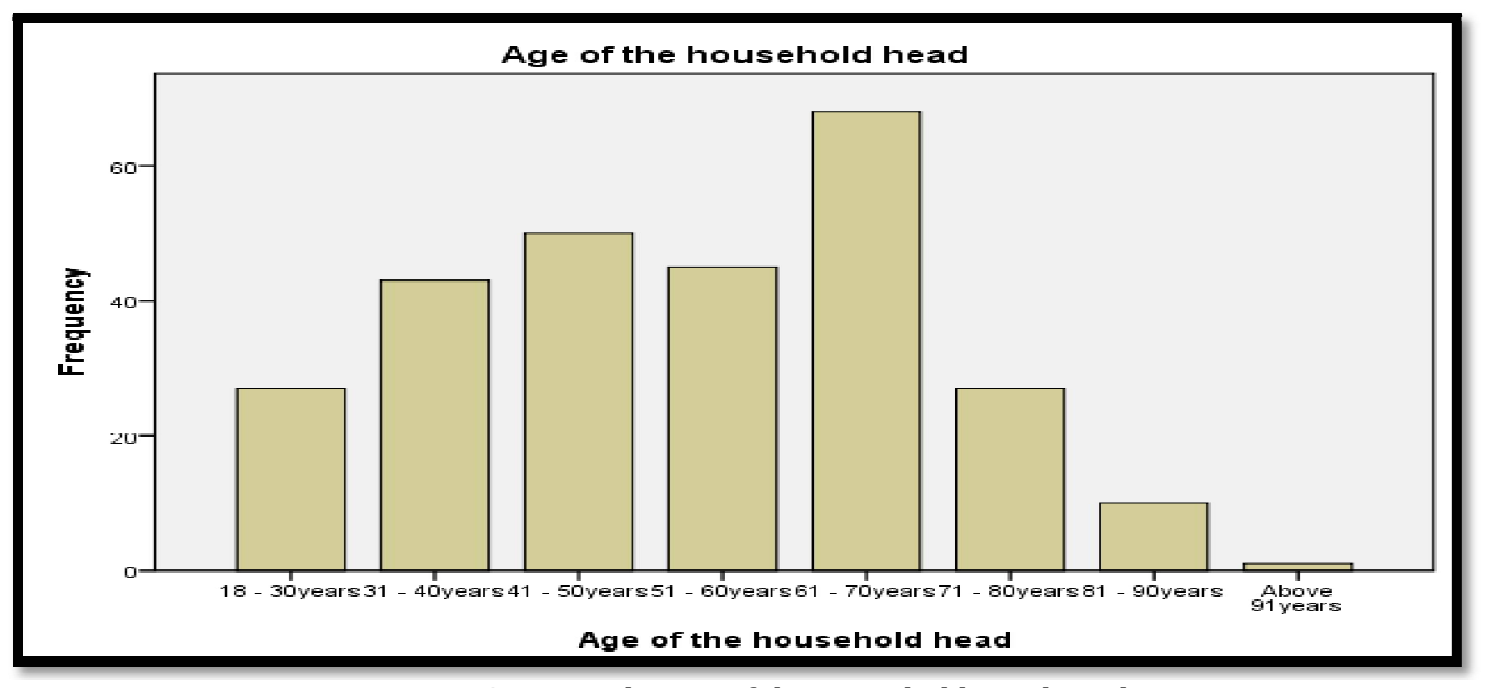

Figure 2: Age Distribution of the Household Heads in the Peri-Urban Slums of Kisumu City

Ninety seven percent (97\%) of inhabitants had access to water (drinking, cooking) while 3\% had no access. Farmer water sources included: tap water from the Kisumu City (68\%), boreholes and nearby wells (17\%), rivers $(11 \%)$, flood water and water ponds (2\%), Lake Victoria (2\%) and water vendors (1\%). Majority (65\%) of farmers had access to agricultural and veterinary extension services while $35 \%$ had no access (see Table 1). Eighty percent $(80 \%)$ of respondents had title deeds while $20 \%$ did not. In addition, $80 \%$ of land was privately owned and $19 \%$ was owned by the community. Less than $1 \%$ of the inhabitants were tenants residing in residential houses and did not own land (see Table 1). The average land size was 0.8 acres. Farmers had an average of 2 contacts per year with agricultural and veterinary extension agents. The average distance to the nearest extension offices was 5 kilometers (see Table 2). 


\begin{tabular}{|c|c|c|}
\hline Variables & Frequency & Percentage \\
\hline \multicolumn{3}{|c|}{ Socio-economic characteristics } \\
\hline \multicolumn{3}{|l|}{ Gender } \\
\hline Male & 156 & 57.56 \\
\hline Female & 115 & 42.44 \\
\hline \multicolumn{3}{|l|}{ Level of education } \\
\hline No formal schooling & 38 & 14.02 \\
\hline Lower Primary & 36 & 13.28 \\
\hline Upper Primary & 97 & 35.79 \\
\hline Secondary & 73 & 26.94 \\
\hline College/University & 27 & 9.96 \\
\hline \multicolumn{3}{|l|}{ Non-farm activities } \\
\hline Yes & 133 & 49.08 \\
\hline No & 138 & 50.92 \\
\hline \multicolumn{3}{|l|}{ Type of non-farm activities } \\
\hline Shops/Kiosk & 79 & 29.15 \\
\hline Livestock trading & 3 & 1.10 \\
\hline Masonry and carpentry & 13 & 4.80 \\
\hline Fishing & 5 & 1.84 \\
\hline \multicolumn{3}{|l|}{ Access to water } \\
\hline Yes & 264 & 97.42 \\
\hline No & 7 & 2.58 \\
\hline \multicolumn{3}{|c|}{ Sources of water (drinking, cooking) } \\
\hline Tap water & 185 & 68.27 \\
\hline Well/borehole water & 46 & 16.97 \\
\hline River water & 30 & 11.07 \\
\hline Flood/water pans & 6 & 2.21 \\
\hline Lakes water & 4 & 1.48 \\
\hline Other (Water vendors) & 1 & 0.36 \\
\hline \multicolumn{3}{|c|}{ Access to veterinary extension services } \\
\hline Yes & 176 & 64.94 \\
\hline No & 95 & 35.06 \\
\hline \multicolumn{3}{|l|}{ System of tenure } \\
\hline With title deed & 216 & 79.70 \\
\hline Without title deed & 55 & 20.30 \\
\hline \multicolumn{3}{|l|}{ Type of land ownership } \\
\hline Private & 218 & 80.44 \\
\hline Community & 52 & 19.19 \\
\hline Other (tenant) & 1 & 0.38 \\
\hline
\end{tabular}

Table 1: Farmer Socio-Economic Characteristics (Categorical Variables)

\begin{tabular}{|c|c|c|}
\hline Variables & Mean & Standard deviation \\
\hline Years of schooling & 8.58 & 4.89 \\
\hline Household size & 7.05 & 3.92 \\
\hline Members involved in income generating activities & 1.70 & 1.56 \\
\hline Years of practicing agriculture & 17.72 & 13.03 \\
\hline Average size of land owned (acres) & 0.80 & 0.94 \\
\hline Contacts with veterinary extension (per year) & 2.02 & 2.82 \\
\hline Distance to nearest veterinary services (Kms) & 5.22 & 3.86 \\
\hline Average number of livestock owned & 21.98 & 21.21 \\
\hline Average household milk consumption litres/day) & 1.33 & 1.30 \\
\hline Average amount of milk sold (litres/day) & 0.44 & 1.62 \\
\hline Average cost of treating livestock (ksh) & 4230.67 & 6473.40 \\
\hline
\end{tabular}

Table 2: Farmers Socio-economic Characteristics (Continuous Variables)

\subsection{Farm and Livestock Production System in the Peri-Urban Slums of Kisumu City}

Inhabitant farmers surveyed had kept livestock for an average of 18 years (see Table 2). Twenty-six (26\%) practiced pure livestock production while $74 \%$ were mixed farmers. Ninety seven percent $(97 \%)$ of cattle kept were indigenous while $3 \%$ were exotic. Reasons for keeping indigenous cattle were: affordability and ease of management $(72 \%)$, disease resistance (16\%) and local availability (4\%). Exotic cattle were kept due to their high milk and meat 
production (see Table 3). Reasons for keeping livestock were: income generation (33\%), cultural purposes (3\%) and domestic consumption (62\%). The main livestock production systems were free range (93\%) and zero grazing (7\%) (see Table 3). Average number of animals per households was 22 (see Table 2). Sixty-six percent (66\%) of farmers used family members as source of labor while (34\%), hired labor. Materials used for constructing ruminant housing were: wooden (35\%), metallic $(24 \%)$, concrete $(5 \%)$ and mud $(11 \%)$. Twenty-five $(25 \%)$ of ruminants were tethered outside the household compound (see Table 3).

\begin{tabular}{|c|c|c|}
\hline Variables & Frequency & Percentage \\
\hline \multicolumn{3}{|l|}{ Farming activities } \\
\hline Livestock production only & 70 & 25.83 \\
\hline Both crop and livestock production & 201 & 74.16 \\
\hline \multicolumn{3}{|l|}{ Type of livestock } \\
\hline Indigenous & 263 & 97.05 \\
\hline Exotic & 8 & 2.95 \\
\hline \multicolumn{3}{|l|}{ Reasons for choice of type livestock } \\
\hline Affordability & 196 & 72.32 \\
\hline Resilience (hardy) & 43 & 15.87 \\
\hline Availability & 12 & 4.42 \\
\hline Others (Norm, lack offeed, income etc) & 20 & 7.38 \\
\hline \multicolumn{3}{|l|}{ Reason for keeping type of livestock } \\
\hline Income & 90 & 33.21 \\
\hline Domestic consumption & 169 & 62.21 \\
\hline Cultural purposes & 8 & 2.95 \\
\hline Others (Collateral, ploughing) & 4 & 1.48 \\
\hline \multicolumn{3}{|l|}{ Livestock farming system } \\
\hline Free range & 252 & 92.99 \\
\hline Zero grazing & 19 & 7.01 \\
\hline \multicolumn{3}{|l|}{ Ruminant housing material } \\
\hline Wooden & 94 & 34.69 \\
\hline Metallic & 65 & 23.99 \\
\hline Concrete & 14 & 5.17 \\
\hline Mud & 31 & 11.44 \\
\hline Other (tethering) & 67 & 24.72 \\
\hline \multicolumn{3}{|l|}{ Source of labor } \\
\hline Family members & 180 & 66.42 \\
\hline Hired & 91 & 33.58 \\
\hline Concrete & 14 & 5.17 \\
\hline Mud & 31 & 11.44 \\
\hline Other (tethering) & 67 & 24.72 \\
\hline \multicolumn{3}{|l|}{ Type of supplement } \\
\hline Market and kitchen left over & 101 & 37.27 \\
\hline Brewer's waste (machicha) & 2 & 0.73 \\
\hline Hay/Napier grass & 19 & 7.01 \\
\hline Commercial supplement & 7 & 2.58 \\
\hline
\end{tabular}

Table 3: Farm and Livestock Production System in the Peri-Urban Slums of Kisumu City

Fifty four percent (54\%) of farmers did not provide supplementary feeds other than natural grazing (see Fig. 3). Forty four percent (44\%) of farmers supplemented their animal feeds using local supplements from the garden and nearby open spaces while $2 \%$ used commercial feeds. Local supplements consisted of kitchen left over's and market waste (37\%), hay and Nappier grass 7\% while less than $1 \%$ consisted of brewer's waste (Machicha) (Table 3). 


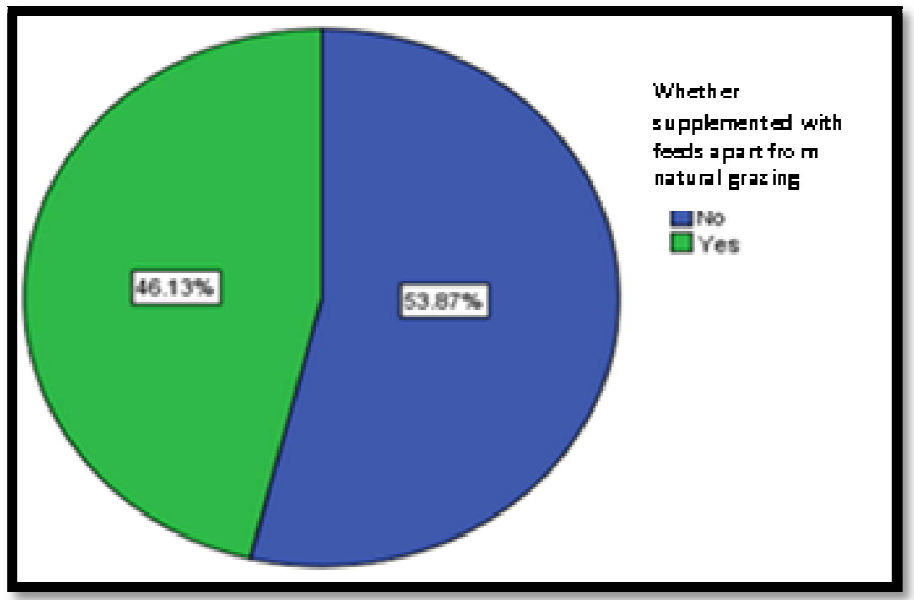

Figure 3: Farmers Using Supplementary Livestock Feeds Apart from Natural Grazing

\subsection{Livestock Production Constraints in the Peri-Urban Slums of Kisumu City}

The results show that $63 \%$ of the farmers milked their cattle while $37 \%$ did not. Milk was produced for domestic consumption (69\%) while (7\%) was sold. The average volume of milk consumed was 1.3 litres and 0.4 litres sold (Table 4). Production constraints included: diseases (65\%), lack of animal feed (19\%), inadequate veterinary services (6\%), stock theft (4\%), lack of labor (3\%), and poor genetic fertility (1\%). and other constraints (2\%) such as: poverty, drought and premature death. Marketing constraints were: low prices for livestock products (42\%), exploitation by middle men (30\%), lack of credit (3\%) and poor infrastructure (2\%) (see Table 4). Sixty-four farmers (24\%) could not identify marketing constraints associated with livestock feeding and production. The most prevalent disease in cattle were: tick-borne diseases (53\%), foot and mouth (15\%), anaplasmosis (4\%), helminthosis (4\%) and anthrax (4\%). Other diseases included: milk fever (0.37\%), foot rot (1.5\%) and black water (3\%) (see Fig. 4).

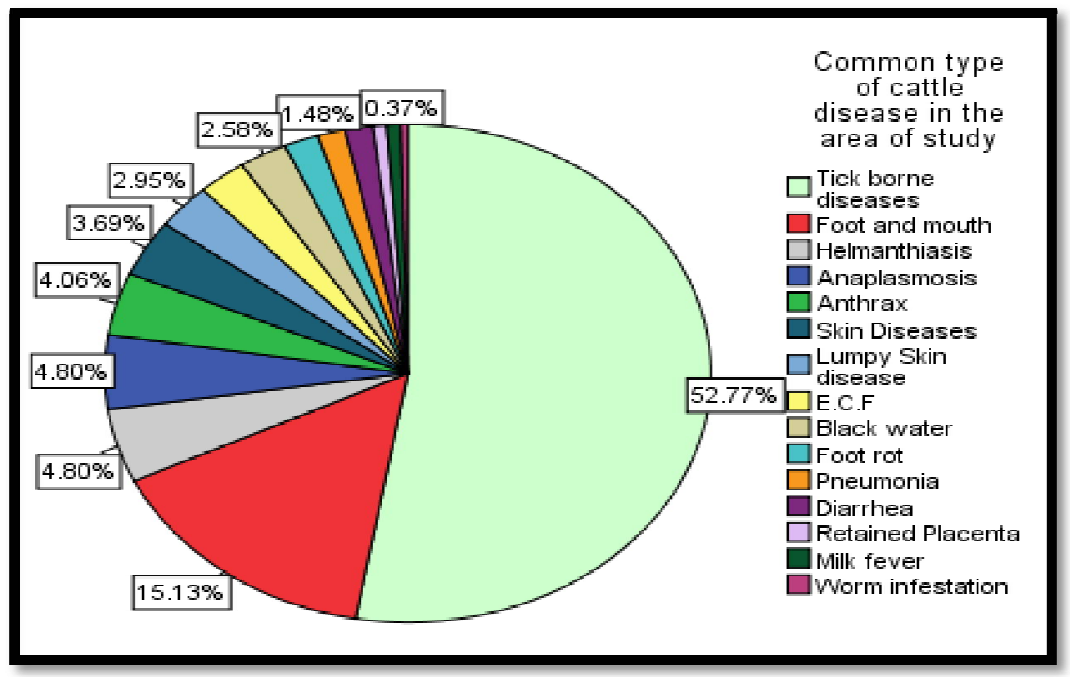

Figure 4: Common Cattle Disease Constraints in the Peri-Urban Slums of Kisumu City

The common pig diseases were: diarrhea (5\%), respiratory infections $(0.4 \%)$, mange $(0.4 \%)$ and African swine fever (3\%). Common poultry diseases were: Newcastle disease (13\%), chicken pox (21\%), diarrhea (33\%) and respiratory infections (24\%) (see Table 4). Ticks were the most common disease transmitters among ruminants. Farmers obtained information on management and treatment of livestock largely from private veterinarians (64\%) (see Table 4). The average cost of livestock production and management at the household level was depicted as 4300 Kenyan shillings (see Table 2). 


\begin{tabular}{|c|c|c|}
\hline Variable & Frequency & Percentage \\
\hline \multicolumn{3}{|l|}{ Milking Livestock } \\
\hline Yes & 171 & 63.10 \\
\hline No & 100 & 36.90 \\
\hline \multicolumn{3}{|l|}{ Milk Utilization } \\
\hline Consumption & 188 & 69.37 \\
\hline Selling & 19 & 7.01 \\
\hline \multicolumn{3}{|l|}{ Production Constraints } \\
\hline Diseases & 175 & 64.58 \\
\hline Lack of Feed & 51 & 18.82 \\
\hline Poor genetic fertility & 5 & 1.85 \\
\hline Lack of labor & 7 & 2.83 \\
\hline Inadequate veterinary services & 16 & 5.90 \\
\hline Stock theft & 12 & 4.43 \\
\hline Other (poverty drought, premature death etc) & 5 & 1.85 \\
\hline Not aware & 0 & 0.00 \\
\hline \multicolumn{3}{|l|}{ Marketing Constraints } \\
\hline Low agricultural prices & 113 & 41.64 \\
\hline Exploitation by middlemen & 82 & 30.26 \\
\hline Lack of credit & 7 & 2.58 \\
\hline Poor infrastructure & 5 & 1.85 \\
\hline Not aware & 64 & 23.62 \\
\hline \multicolumn{3}{|l|}{ Common chicken diseases } \\
\hline Newcastle disease & 39 & 13.39 \\
\hline Respiratory Infections & 65 & 23.99 \\
\hline Chicken pox & 58 & 21.40 \\
\hline Diarrhea & 89 & 32.84 \\
\hline Others (lameness, theft etc) & 3 & 1.11 \\
\hline Not aware of any diseases & 17 & 6.27 \\
\hline \multicolumn{3}{|l|}{ Source of agricultural information } \\
\hline Private veterinarians & 172 & 63.47 \\
\hline Government veterinarians & 27 & 9.96 \\
\hline Agro-Vet Shops & 47 & 17.34 \\
\hline Farmer to Farmer & 27 & 9.96 \\
\hline Radio & 12 & 4.43 \\
\hline Television & 4 & 1.48 \\
\hline Farm magazines & 1 & 0.37 \\
\hline Others(Agricultural exhibitions, relatives) & 8 & 2.95 \\
\hline
\end{tabular}

Table 4: Constraints to Livestock Production in the Peri-Urban Slums of Kisumu City

\section{Discussion}

The objective of this study was to determine the risk factors associated with livestock feeding and disease control practices in the peri-urban slums of Kisumu City, Kenya. The results showed that (93\%) of inhabitant farmers grazed their animals in open land spaces, particularly government and metropolitan lands. These findings concur with those of Mougeot, 2000; Mekuriaw, 2014, who reported that urban livestock farmers grazed livestock along roadsides and in waste dumps. The presence of unfenced open land often acts as alternative grazing fields for urban livestock keepers. Grazing by the road sides and in rubbish dumpsites is not only a nuisance, but also poses a food safety risk for the transmission of zoonotic diseases.

As in many other African societies, most of the families in the current study were male-headed (58\%). In this study, most farmers, (55\%) were more than 45 years old and had been keeping livestock for a period of more than 15 years. Animals were kept mainly for domestic food and financial purposes, and ownership rights were vested primarily in men. These finding concur with those by (Jacobi et al., 2000; Slater, 2001; Danso et al., 2004), who reported that men mostly owned livestock while women claimed a few to no assets. Majority of the farmers kept ruminants, pigs, chicken and ducks and had an educational level ranging from lower primary to tertiary suggesting that exposure to basic or higher education might make it easier to educate farmers on improved livestock production and help them diversify the types of animals kept for increased income. The average land size owned by peri-urban slum farmers within Kisumu City was 0.8 acres. This observation is similar with findings in Kumasi city, Ghana, Drechsel et al. (2003), who reported, that $85 \%$ of the livestock kept were on small plot-sized packages of land of less than a half of an acre as opposed to rural areas where land sizes are relatively bigger. Most of the urban farmers have small land parcels which could hinder livestock production and other farming strategies.

Majority (97\%) of the Kisumu city peri-urban slum farmers kept indigenous cattle while $3 \%$ kept exotic breeds of cattle. This is in contrast with findings by Smith (2010) who reported that small-scale dairy farming characterized with 
exotic breeds was widespread in many sub-Saharan cities such as Nairobi and Dar es salaam. Lack of intensive farming within Kisumu city peri-urban slum livestock keepers could be attributed to less farmer education and minimum exposure to modern agricultural technology. Exotic livestock are frequently affected by diseases which could discourage Kisumu Cityperi-urban slum farmers from keeping them. As reported elsewhere, Kisumu is tropical in nature, livestock could be prone to vector-bone diseases caused by various ect- and endo-parasites. This could be the main reason why indigenous animals where kept since they are resilient and require minimal animal health care and farm inputs. These findings concur with those by Mlozi et al. (1992) who reported that urban farming in developing nations, especially tropical areas faces numerous limitations viz: animal diseases, low prices of agricultural products, conflicts, poor genetic fertility and exploitation by middlemen.

The main cattle diseases constraints to livestock production in Kisumu County were: tick-borne diseases, foot and mouth, anaplasmosis, helminthosis, anthrax, diarrhea, milk fever, foot rot and black water. These constraints have been cited by other studies conducted in cities in developing countries, Graefe et al., (2008) and Barnes et al., (2018), who reported that cattle diseases such as anthrax, tick-borne diseases and black water were widespread in tropical subSaharan Africa and could be attributed to unlawful animal movements to neighborhood markets and abattoirs. The rampant disease incidence within the peri-urban slum livestock keepers in the citycould be attributed to the free-range livestock production system that is widespread in the areas of study.

Farmers interviewed mainly relied on private veterinarians (63.47\%), government veterinarians (10\%), and Agro-Vet Shops (17.34\%) for advice on management and treatment of livestock ailments. In Kumasi, Ghana, 39\% of livestock keepers reported that they used the government veterinary service for animal health care problems but they also carried out many treatments themselves, (Poynter, 2001). In this study, most of the extension service providers were located at an average distance of $5 \mathrm{~km}$ from each farm and thus farmers would not be able to walk to their premises and seek their services. It is probably, the long distance to veterinary offices that contributed to farmers utilizing the alternate readily available private veterinarians and Agro-Vet Shops in this study. This type of scenario was also observed in the City of Kumasi, Ghana, by Afrane et al. (2004) who reported that over half of livestock farmers utilized private veterinarians for advice on livestock management as opposed to the government once. Studies elsewhere, in the rural Busia city, Kenya, Machila et al. (2003) reported that lack or absence of veterinary services caused farmers to traverse long distances to access them leading to many livestock deaths in the rural and urban farming communities. The extension services in Kenya were privatized in late 1980s as part of the World Bank Structural Adjustment Programme, (Oruko et al. 2000), the scenario was complicated by the creation of 47 county governments under which veterinary services were fully devolved and underfunded. This has created a negative impact on veterinary service extension service delivery as most resource poor farmers are unable to pay for the services of either government or private veterinarians (Oruko et al. 2000). With the high level of poverty amongst the peri-urban slum livestock farmers, subsidized veterinary extension services could easily improve the control of major livestock disease constraints and thus ensure food security in the cities.

\section{Conclusions}

- The livestock feeding practice in the peri-urban slums within Kisumu City can be described as open free-range grazing production system characterized by animals grazing along the roadsides, open government metropolitan land spaces and in waste dumpsites which is not only a nuisance, but poses a food safety risk for the transmission of zoonotic diseases.

- Majority of the peri-urban slum farmers practiced mixed farming engaging in both livestock and crop production and nearly all farmers kept indigenous cattle as opposed to exotic.

- The main production identifiable production constraints were diseases (tick-borne diseases and foot and mouth) and lack of animal feeds.

- Major of the risks associated with livestock feeding in peri-urban slums of Kisumu City were: zoonosis, diseases (tick-borne, helminthosis), dumpsites feeds contaminated with toxic materials and natural grazing on poor quality pastures.

- Urban slum farmers relied mainly on private veterinarians and Agro-Vet Shops for advice on management and treatment of livestock ailments.

- $\quad$ Based on these conclusions the project developed policy statement for adoption by the County Government of Kisumu to reduce the risks associated with livestock feeding practices the city.

\section{Acknowledgements}

This work was funded by National Research Fund, (NRF) Kenya. Field logistics were provided by personnel of the Kisumu County Veterinary office, for which the authors are extremely grateful. The authors deeply acknowledge dedicated efforts by technical staff from the Faculty of Veterinary Medicine at Egerton University, the Kenya Agricultural and Livestock Research Organization (KALRO) and the Central Veterinary Laboratories, Kabete.

\section{References}

i. Afrane, Y. A., Klinkenberg, E., Drechsel, P., Owusu-Daaku, K., Garms, R. and Kruppa, T., (2004). Does Irrigated Urban Agriculture Influence the Transmission of Malaria in the City of Kumasi, Ghana. Acta Tropica, 89 (2), 125134.

ii. Barnes, A. N., Mumma, J., and Cumming, O., (2018). Role, Ownership and Presence of Domestic Animals in Peri-Urban Households of Kisumu, Kenya. Zoonoses and Public Health, 65(1), 202-214. 
iii. CAC (Codex Alimentarius Commission)., (2004). Code of hygienic practice for milk and milk products. CAC/RCP 57-2004. Food and Agriculture Organization, Rome.

iv. Danso, G., Cofie, O., Annang, L., Obuobie, E. and Keraita, B., (2004). Gender and Urban Agriculture: The Case of Accra, Ghana. Accra, Ghana: Resource Centre on Urban Agriculture and Forestry (RUAF).

v. Drechsel, P., Keraita, B. and Amoah, P., (2003). Influence of Urban Wastewater on Stream Water Quality and Agriculture in, and Around Kumasi, Ghana. Environment and Urbanization, 15(2), 171-178.

vi. FAO. (2007). Animal Feed Impact on Food Safety (Version 2.2). Rome. Italy.

vii. Graefe, S., Schlecht, E. and Buerkert, A., (2008). Opportunities and Challenges of Urban and Peri-Urban Agriculture in Niamey, Niger. Outlook on Agriculture, 37(1), 47-56.

viii. Ishagi, N., Ossiya, S., Aliguma, L. and Aisu, C., (2002). Urban and Peri-Urban Livestock Keeping Among the Poor in Kampala City. Ibaren Konsultants, Kampala, Uganda.

ix. Jacobi, P., Amend, J. and Kiango, S., (2000). Urban Agriculture in Dar es Salaam: Providing an Indispensable Part of the Diet. Urban agriculture on the policy agenda, 1, 257-283.

x. KNBS (Kenya National Bureau of Statistics). (2018). Population Projections: Analytical Report on Population Projections (Volume 8). Nairobi, Kenya: Kenya National Bureau of Statistics.

xi. Machila, N., Wanyangu, S. W., McDermott, J., Welburn, S. C., Maudlin, I. and Eisler, M. C., (2003). Cattle Owners' Perceptions of African Bovine Trypanosomiasis and its Control in Busia and Kwale Districts of Kenya. Acta tropica, 86(1), 25-34.

xii. Maoulidi, M., (2012). Kisumu millennium development goals multi-sector household survey. New York: Earth Institute, Columbia University.

xiii. Mekuriaw, Y., (2014). Assessment of pig production and constraints in Mecha district, Amhara region, Northwestern Ethiopia. Advances in Agriculture, 1, 34-40.

xiv. Mlozi, M. R., Lupanga, I. J. and Mvena, Z. S. K., (1992). Urban Agriculture as a Survival Strategy in Tanzania. The Rural-Urban Interface in Africa: Journal of Expansion and adaptation, 2(1), 284-294.

xv. Mougeot, L. J., (2000). Urban Agriculture: Definition, Presence, Potentials and Risks, and Policy Challenges. Cities feeding people series, 1, 31-67.

xvi. Oruko, L. O., Upton, M., McLeod A., (2000). Restructuring of animal health services in Kenya: constraints, prospects and options. Development Policy Review 18: 123-138.

xvii. Poynter, G., (2001). Findings into a survey of urban livestock in Kumasi Ghana. Msc thesis, University of Edinburgh, Edinburgh, UK

xviii. Schiere, H., Tegegne, A. and Veenhuizen, R., (2000). Livestock in and around Cities. Urban Agriculture Magazine, 1, 11-24.

xix. Shimshoni, J. A., and Barel, S., (2017). Recent trends in common chemical feed and food contaminants in Israel. Journal of Environmental Science and Health, Part C, 35(4), 189-212.

xx. Slater, R. J., (2001). Urban Agriculture, Gender and Empowerment: An Alternative View. Development Southern Africa, 18(5), 635-650.

xxi. Smith, D., (2010). Cities Feeding People: An Update on Urban Agriculture in Equatorial Africa. Environment and Urbanization, 22(2), 483-499.

xxii. Waters, E. K., Hamilton, A. J., Sidhu, H. S., Sidhu, L. A. and Dunbar, M., (2016). Zoonotic Transmission of Waterborne Disease: A Mathematical Model. Bulletin of Mathematical Biology, 78(1), 169-183. 